\title{
Overheden niet goed in innovatie?
}

\section{Empirische verkenningen van een 'innovatiedilemma'"}

\author{
Geert Teisman, Haiko van der Voort \& Albert Meijer
}

\begin{abstract}
Deze bijdrage bevat een samenvatting en een conclusie van het themanummer 'Innovaties en overheden: een slecht huwelijk of een vruchtbaar rollenspel?'. Overheden zijn goed in innovatie, maar dit is weinig zichtbaar. Overheden hebben namelijk een ingewikkelde positie in innovatie. Innovatie brengt vrijwel altijd strijdigheid tussen publieke belangen aan het licht. Burgers verwachten van overheden dat ze hun belangen borgen. De overheid moet dus altijd voor innovatie zijn en tegen mogelijke schade aan publieke belangen. We noemen dit het innovatiedilemma. De vier bijdragen laten zien hoe overheden met dit dilemma omgaan. Ze bewegen in eerste instantie mee met de innovatie, om vervolgens hun positie te herdefiniëren. Ze ontwikkelen bijvoorbeeld nieuwe instrumenten, ze bundelen private initiatieven of ze framen deze initiatieven tot grote programma's. Dit themanummer agendeert verder onderzoek naar bijdragen van overheden aan de publieke waarde van innovatie.
\end{abstract}

Zonder innovatief vermogen was de mens nog gelijk een aap geweest. De mens is een homo faber: via vernieuwingen krijgt hij grip op zijn omgeving. Bedrijfskundigen stellen dat innovatie noodzakelijk is om te overleven. Beroemde bedrijfskundige modellen zijn de S-curve van Rogers (1995), die innovatieprocessen in de tijd afbeeldt in een S-vormige grafiek, het Stage-gate innovatieproces van Cooper (1990), waarin innovatieprocessen in fasen en met expliciete beslismomenten verlopen, en Agile-innovaties (Highsmith \& Cockburn, 2001), waar de wens van de klant onduidelijk en veranderlijk wordt verondersteld en innovaties op zoek zijn naar echte verlangens.

Het denken over innovatie gebeurt dus vooral in de bedrijfskunde. De overheid wordt zelden gezien als innovator. Mede daarom besteedt de bestuurskunde er wellicht minder aandacht aan. De overheid met haar voorkeur voor bureaucratische structuren is meer gericht op stabiliteit en voorspelbaarheid en minder op vernieuwing en verandering.

Mazzucato (2013) stelt dat beeld ter discussie. Zij beschrijft overheden als ultieme durfkapitalisten. Dankzij publieke investeringen en acties kunnen innovaties van bedrijven als Apple en Google zich ontwikkelen en verspreiden. Haar boek heeft een internationaal debat aangejaagd over de vraag of overheden innovatieschuw en innovatieloos zijn, of inderdaad de door Mazzucato geschetste rol

* $\quad$ Prof.dr.ing.G.R. Teisman, Hoogleraar Bestuurskunde; Erasmus Universiteit Rotterdam

Dr. H.G. van der Voort, Universitair Docent Bestuurskunde; TU Delft

Prof.dr. A.J. Meijer, Hoogleraar Bestuurskunde; Universiteit Utrecht 
bij grote innovaties heeft en kan blijven houden. Empirische studies zijn nodig om dit debat te verrijken. Om deze reden stelt dit themanummer de vraag over innovatief vermogen van overheden centraal.

In de bestuurskundige literatuur wordt vaker over 'verandering' dan 'innovatie' geschreven. 'Verandering' duidt op langdurige en weerbarstige processen waarin 'sturing' door overheden wordt geproblematiseerd. Daarbij gaat het om complexe processen in netwerken, en van verschillende publieke en private belangen. Er wordt veel verwacht van samenwerking tussen overheden, burgers en het bedrijfsleven. Relaties, vertrouwen, interactie tussen publiek en privaat worden als voorwaarde voor grote innovaties gezien (Spekkink, Teisman en Boons, dit themanummer).

De afgelopen tien jaar is het onderzoek naar innovatie in de publieke sector gegroeid (De Vries, Bekkers, \& Tummers, 2015). Daarbij ging het vooral om innovatie in de publieke dienstverlening (Osborne \& Brown, 2005). De laatste jaren wordt meer gekeken naar innovatie in de aanpak van maatschappelijke vraagstukken. Hiervoor wordt de term social innovation gebruikt (Brandsen, Cattacin, Evers \& Zimmer, 2016). In deze lijn van onderzoek wordt voortgebouwd op inzichten over netwerkmanagement en staat de notie van collaborative innovation centraal: overheden werken samen met andere partijen om vernieuwende oplossingen voor (lokale) maatschappelijke vragen te ontwikkelen (Sørensen \& Torfing, 2011). In aanvulling op deze literatuur, die inzoomt op specifieke - vaak kleinschalige innovaties, zijn er ook studies die zich richten op de rol van de overheid in grotere transities. Bij modellen als transitiemanagement (Rotmans, 2003) en strategisch nichemanagement (Kemp, Schot \& Hoogma, 1998) blijft de inhoudelijke rol van overheden beperkt, maar kunnen overheden wel ruimte scheppen voor nichespelers. Bij transitiemanagement participeren overheden in het formuleren van langetermijndoelen. Bij strategisch nichemanagement zijn het vooral voorwaarden voor innovatie die bewaakt moeten worden. Daarbij is niet uitgesloten dat een publieke partij dat doet. In de kanteling van governance en minder van government, zo klinkt het sinds de jaren negentig, hoeven en kunnen overheden niet inhoudelijke innovaties te initiëren en ze vervolgens aan andere partijen op te dringen.

Het publieke domein is om minstens twee redenen anders dan het private domein. Ten eerste verschillen de consequenties van het succes van innovaties. Innovaties in het publieke domein kennen net als in het bedrijfsleven winnaars en verliezers. Echter, in tegenstelling tot het bedrijfsleven, waar de verliezers verdwijnen en de winnaars met trots de opbrengst van hun innovaties in bedrijfscijfers, shareholder value en trotse werknemers kan laten zien, blijven de winnaars en verliezers in het publieke domein bestaan en blijven ze met elkaar in het gevecht om de macht. Ten tweede verwachten mensen iets anders van overheden dan van bedrijven. Elke innovatie draagt ook destructie met zich mee. Van overheden wordt, meer dan van bedrijven, verwacht dat ze de gevolgen van destructie matigen. Velen vinden bijvoorbeeld TTIP een noodzakelijke innovatie in vrijhandel om de economie verder te ontwikkelen, terwijl vele anderen het een bewijs van neergang vinden waardoor hun werkplek op de tocht komt te staan. Dat geldt ook voor bijvoorbeeld robotisering: deze ontwikkeling wordt gezien als de sleutel 
tot economische groei maar ook als een bedreiging voor de werkgelegenheid. Overheden worden geacht de verliezers niet aan hun lot over te laten. Men verwacht dat ze manieren vinden om niet alleen de baten van innovaties te benutten maar ook de nadelige effecten te minimaliseren.

Het bovenstaande geeft aan dat de mogelijke rollen van overheden bij innovaties divers zijn. Ons begrip van deze rollen is echter beperkt. Welke rollen kunnen overheden spelen bij innovaties? We nemen uit de bestuurskundige literatuur mee dat innovatieprocessen complex zijn, dat er meerdere partijen bij betrokken zijn, die geen van allen hun wil kunnen opleggen aan de ander. Bij productinnovatie kunnen sommige partijen nog zelfstandig hun gang gaan, bij maatschappelijke innovaties wordt dat moeilijk. Deze vergen interactie tussen overheden en andere partijen. In deze afsluitende bijdrage combineren we de inzichten van de vier bijdragen tot een samengesteld beeld over de rol van overheden.

\section{Vier innovaties, vier risico's voor publieke waarden}

Frenken adresseert de opkomst van de deeleconomie, een fenomeen dat de kranten regelmatig haalt. Hij beschouwt deze als maatschappelijke 'doorbraakinnovatie', waarbij spanning optreedt tussen de deugden van de innovatie en de bestaande regelgeving. Hier zien we al waar een deel van het beeld vandaan komt en waarom overheden innovatievijandig lijken te zijn. Ze zijn verantwoordelijk voor regelgeving, waaronder publiekrechtelijke regelgeving, en juist deze laatste gaat overwegend uit van het bestaande en bepaalt daarin alles wat mag. In de casus van Frenken ontstaat een alternatieve economie van delen tussen peers, naast de met regelgeving geleide, bestaande economie van professionele bedrijven die diensten aan burgers leveren. De laatstgenoemde vorm is gereguleerd, om de veiligheid van klanten te borgen, te zorgen voor belastinginkomsten en te voorkomen dat derden grote hinder ondervinden van privaat initiatief. De 'deeleconomie' onttrekt zich aan deze conventies. Wat mensen onderling delen, kan bijvoorbeeld moeilijk op veiligheid worden getoetst.

De vraag doet zich dan voor hoe de waarden die aanleiding zijn geweest voor de regelgeving in de reguliere markt te borgen zijn in de deeleconomie. Hiervoor moeten niet de reguliere productiebedrijven zorgen. De oplossing lijkt om mondiale platformen van prosumenten (mensen die productie en consumptie laten fuseren) of lokale peers te bewegen publieke waarden te respecteren. Vanwege de positieve bijvangsten van de deeleconomie, onder meer in de vorm van efficiënter gebruik en minder verspilling en in de vorm van sociale cohesie, lijkt dit aantrekkelijk. De worsteling met Airbnb, in feite een hybride van 'opportunistisch' ondernemerschap en deeleconomie en de snelle infiltratie door winstgerichte ondernemers in deze vorm van deeleconomie, laat zien dat ook hier de overheid iets even toestaat, maar zich vervolgens wel weer afvraagt hoe het zit met derden-belanghebbenden (zoals de buren van Airbnb-huizen) en hoe ook hieruit belastingmiddelen zijn te halen. De overheid reguleert innovaties die haar overkomen, zouden we kunnen leren uit de bijdrage van Frenken. En dat is een netelig vraagstuk. Te veel rem schaadt de ontwikkeling, te veel ruimte schaadt het maatschappelijk ver- 
trouwen in ontwikkeling. De zo mooi klinkende creatieve destructie is dan te beangstigend voor de burger-verliezers.

De bijdrage van Spekkink, Teisman en Boons gaat juist over interactie tussen publiek en privaat waarin overheden een schakel vormen tot innovatie, niet op het niveau van projecten, maar op het niveau van branding. De casus gaat over innovatie in industriële clusters. De auteurs vragen zich af welk rollenspel zich tussen publieke en private partijen ontvouwt bij initiatieven ten behoeve van duurzaamheid. Hiertoe beschrijven zij twee cases waarin partijen in het licht van het idee van een transitie naar een circulaire economie tradeoffs tussen duurzaamheid en economische mogelijkheden verkennen en realiseren. Hier zien we mooi terug dat bedrijven overwegend beter zijn in productinnovatie en innovatie in productieprocessen. Deze spelen zich tussen bedrijven af die elkaar hebben gevonden en vertrouwen. Daarmee kunnen in een regio vanuit het zelforganiserende vermogen van partijen veel productieprocesinnovaties plaatsvinden. Bedrijven spelen hier op in ten behoeve van hun overleving of winstgevendheid, niets mis mee. Een duurzame economie is evenwel een maatschappelijk vraagstuk, waarbij een publiek doel is om de ideeën ook bij anderen dan koplopers bekend te maken en door te laten voeren. Daarvoor is het nodig dat bedrijven van elkaar leren. Dat is evenwel niet een kernbelangstelling noch kernkwaliteit van bedrijven. Ze willen hun concurrenten niet wijzer maken dan ze al zijn, of op zijn minst niet al te wijs. En juist dan kunnen publieke organisaties met kennis van zaken, zoals in hun casus een publiek havenbedrijf met veel affiniteit voor het private, een centrale rol spelen. De auteurs laten zien dat dit niet de centrale rol is van een bovengeschikte overheid die andere partijen aanstuurt, maar een partij die haar centrale rol juist krijgt door in betweenness centrality (Freeman, 1978): een vertrouwenspositie te midden van actoren die invloed mogelijk maakt. De overheid is dus invloedrijk door iets te kunnen en doen wat bedrijven niet snel doen. Dit is een mooi voorbeeld van een effectieve publiek-private samenwerking, zonder dat er ook sprake hoeft te zijn van aanbesteding of contract.

De bijdrage van Meijer, Tomor, Michels en Geertman beschrijft de manier waarop steden omgaan met door technologie mogelijk gemaakte burgerinitiatieven. Het gaat om het heruitvinden van effectieve interactie tussen burger en overheid in de publieke ruimte. Het heruitvinden betreft de manier waarop overheden met hun burgers omgaan. Opvallend is dat de auteurs zich zorgen maken over procedurele waarden die normaliter in het publiekrecht zijn geborgd, zoals derdenbelanghebbenden. Ook zij zoomen daarmee snel in op de rol van de overheid om nadelen van innovaties te matigen. Ze vragen zich bijvoorbeeld af of burgerinnovaties wel namens alle burgers ontwikkeld worden. Brede representatie en inclusie zullen bij innovaties gauw in de verdrukking raken, juist omdat het gaat om koplopers. Als deze moeten wachten op het peloton, gaan ze al snel niet veel meer doen dan meefietsen.

Maar ook hier is een enerzijds-anderzijds. Sommigen bestempelen burgerinitiatieven juist als vitale democratie, omdat burgers de mogelijkheid hebben tot directere (en vaak goedkopere) zeggenschap over hun omgeving. Zij kunnen als het ware de kracht van de participatiesamenleving voorleven. Anderen zullen het democratische gehalte juist betwijfelen indien niet iedereen de mogelijkheid heeft 
directe zeggenschap te verkrijgen. Deze spanning zal ongetwijfeld blijven terugkomen in het politieke debat. Innovatie en gelijkheid vechten hier om voorrang, een thema dat in de bedrijfskunde niet of op zijn minst veel minder centraal staat. In het publieke domein is innovatie niet los te zien van de creatieve destructie, in het bedrijfsleven vindt dit plaats als onderdeel van de marktwerking.

De bijdrage van Van Buuren en Ellen zoomt in op kerntaken van de overheid en de vraag hoe innovatie daar mogelijk is. De casus die zij presenteren, behelst het waarborgen van waterveiligheid, in Nederland sinds jaar en dag een klassieke overheidstaak. De waterschappen vormen oude bestuursorganisaties, waar menig buitenland jaloers op is. Heruitvinden betreft hier de manier waarop de publieke taak wordt uitgevoerd. Om de veiligheid in de toekomst te blijven waarborgen achten betrokkenen innovatie noodzakelijk. En juist hier zien een innovatieschuwheid van overheden. Innovaties vormen een bedreiging voor de dagelijkse gang van zaken, waarop het bestaan van publieke organisaties is gebaseerd. De dagelijkse praktijk is rijk aan regels, die zorgen dat publieke organisaties diensten leveren die de burger beschermen, maar die innovaties in de weg staan. Het moet eerst heel duidelijk worden dat de huidige aanpak niet meer kan, voordat echte veranderingen in de aanpak worden doorgevoerd.

Alle bijdragen verklaren een deel van de vraag waarom overheden moeite hebben met innovaties. Ze missen de kennis van private partijen (Spekking et al.), ze moeten de nadelen zwaar meewegen (Meijer et al.), ze moeten schipperen tussen burgers die goed meekunnen en burgers die dat niet kunnen (Frenken), en ze moeten zich ontworstelen aan hun eigen natuur van regelgeleid gedrag (Van Buuren et al.). Waar in de private sector de slogan 'Innovate or die' domineert (Matson, 1996), en er daarmee een sterke beloning aanwezig lijkt voor innovatie, geldt voor de overheid veeleer een 'innovatiedilemma'. Innovatie herbergt nastrevenswaardige beloftes voor de publieke zaak, maar is voor delen van zowel de overheid als burgers onontkoombaar een bedreiging. Zij moeten veranderen zonder de voordelen van de innovatie te kunnen genieten. Die delen van de overheid en publiek zullen bestaande institutionele kaders die innovatie in de weg kunnen staan, eerder koesteren dan willen aanpassen, ook al zijn deze toegespitst op een tijd die lijkt te vervliegen. En daarmee beginnen we steeds beter te begrijpen waarom we overheid niet associëren met innovatie. We onthouden waarschijnlijk meer en beter haar mitigerende en frustrerende werking. En ook begrijpen we nu beter dan eerst dat dit beeld een vertekening is en dat Mazzucato ook gelijk heeft. De overheid kan iets wat bedrijven minder goed kunnen, namelijk het opschalen van innovaties en het versnellen ervan door anderen mee te laten leren.

Een logische vervolgvraag is hoe overheden met het 'innovatiedilemma' omgaan. Uit de bijdragen kan niet worden afgeleid dat overheden grote weerstand hebben tegen innovaties. We houden het voor mogelijk dat dit aan de selectie van auteurs en thema's kan liggen, maar de studies omvatten een breed terrein en laten zien dat innovatie geen fremdkörper is in de publieke sector. Overheden blijken zich bewust van de deugden van de innovatie, maar al snel worden ze aangesproken op de problemen die ontstaan door de creatieve destructie die samengaat met innovatie. De overheid is immers ook en misschien wel meer voor het matigen van 
problemen dan het grijpen van kansen, lijken de artikelen te bevestigen. We zien in de vier cases een opvallend patroon.

\section{Overheden bewegen eerst mee met de innovatie ...}

Zodra nieuwe technologie burgers de mogelijkheid schenkt hun overgebleven capaciteit te delen met anderen, ontstaat spontaan een deeleconomie. Frenken leert ons dat de gemeente Amsterdam en het ministerie van Economische Zaken vooral zachte beleidsinstrumenten inzetten om de innovators en hun peers te verleiden publieke belangen te respecteren. Tegelijkertijd wordt contact gezocht met mondiaal opererende platformen voor afspraken. De overheid probeert te bemiddelen tussen partijen, zouden we kunnen stellen.

Dat idee van overheden met een centrale positie en bemiddeling tussen partijen wordt een stuk verder gebracht door Spekkink, Teisman en Boons. Zij laten zien dat overheden dankzij hun in betweenness centrality tussen private partijen, die elkaar zien als concurrenten of elkaar niet zien, aanvullend, verbindend en uiteindelijk opschalend kunnen inspringen op private innovaties in industriële clusters. Overheden kunnen vanuit hun publieke doelen beter programmatisch nadenken over de ontwikkeling van 'ecoindustrial parks en clusters', identificeren de auteurs. Ze kunnen dat programma echter pas vullen wanneer er interactie met een aantal naast elkaar bestaande, autonome, private projecten ontstaat. Ze laten zien dat hier gedeelde grond ontstaat voor een programmatische innovatie en dat sommige ambtenaren zich ontwikkelen tot verbindingspersonen. Dat identificeren zij als de voorwaarden waaraan moet worden voldaan, alvorens overheden zich kunnen opmaken voor een belangrijke programmatische rol. Er moet dus wel een beweging zijn voordat overheden kunnen meebewegen. De nieuwe rol die deze auteurs zien, is die van tussenpartij, mooi gemunt in de term in betweenness centrality.

De bijdrage van Meijer, Tomor, Michels en Geertman laat overheden zien die burgers willen aanwenden voor eigen dienstverlening. Ook dit fenomeen kennen we reeds lang uit de bedrijfskunde, waar bedrijven steeds meer van hun werk gratis laten doen door hun klanten. De supermarktklant die zijn producten zelf uit de schappen haalt, is al bekend. De volgende stap is dat hij ze ook zelf scant en afrekent. We zien momenteel de telebankierende burger, die steeds meer zelf doet en een revolutie in de bankwereld uitlokt met alle bijkomende schade op korte termijn die daarbij hoort. Een vergelijkbare stap voltrekt zich mogelijk in het publieke domein. De participatiesamenleving is daarvan het overkoepelende label en nieuwe technologieën faciliteren dit: ze maken de burger 'leesbaar'. De data van burgers worden aangewend om het dienstverlenend vermogen van de overheid aan te vullen en te versterken. Hierbij maken ze eerst gebruik van burgers als databron en stellen dan pas de meer fundamentele vraag of ze niet alleen willen innoveren vóór de burgers, maar ook mét hen. De technologie creëert eerst een nauw perspectief op innovatie, dat zich pas later lijkt te verbreden naar meer actieve participatie. Daarmee is meebewegen met de technologische mogelijkhe- 
den voor overheden een slimme strategie om het eigen functioneren te verbeteren.

Innovaties in waterveiligheidsbeleid komen in een overheid-gedomineerde sector niet snel van buiten. Er is geen sprake van 'meebewegen'. Wel kan sprake zijn van een overheid als launching customer, die door uitdagende verzoeken in de markt te zetten bedrijven tot innovaties kan aanzetten, die ze daarna nog jaren elders in Nederland of in het buitenland kunnen afzetten. Van Buuren en Ellen laten zien dat voorgenomen innovatie en bestaande, gereguleerde operatie op gespannen voet staan met elkaar. In feite neemt een overheid eerst afstand van zichzelf. Vanuit een erkenning dat het primaire proces sterk is geïnstitutionaliseerd en niet vatbaar is voor verandering, wordt niet direct de confrontatie aangegaan tussen de voorgenomen innovatie en de operatie van de 'thuisorganisaties'. In plaats daarvan worden pilots ontwikkeld. Maar dat blijkt dan weer uitstel van executie, want na een geslaagde pilot is de weerstand van bestaande instituties en werkwijzen niet geslecht. In dat opzicht lijkt innovatiekracht gebaat bij een gemengde constellatie van publieke en private partijen.

\section{... en herdefiniëren daarna hun positie}

Ook het effectief beschermen van publieke belangen kan aanzetten tot innovaties. Indien het institutionele kader dat publieke belangen borgt, niet meer voldoet of ontbreekt bij specifieke particuliere of private innovaties, dan is een nieuw antwoord nodig. De overheid wordt uitgedaagd om een nieuwe positie in te nemen. We zien overheden die hun meerwaarde vinden in betweenness centrality in innovatieketens en netwerken. Dat is een belangrijk inzicht. We zien ook overheden die hernieuwd grip aan het zoeken zijn. Alle bijdragen leveren hierover interessante concepten aan, toegespitst op de specifieke situatie die de auteurs beschrijven.

Voor de deeleconomie ontbreekt vooralsnog een institutioneel kader, dat de opbrengst van delen van de oogst en tegelijkertijd de perverse bijvangsten mitigeert. Hierbij is sprake van een 'omgekeerde technologiebeoordeling': in plaats van de nieuwe technologie eerst te toetsen alvorens deze op de markt te brengen, komt deze eerst op de markt en stuurt de overheid achteraf bij.

De instrumenten die overheden gebruiken, zijn vooralsnog zacht. Hierbij past het voornemen van het ministerie van Economische Zaken doelregelgeving toe te passen in plaats van middelenregelgeving: er wordt ruimte gelaten aan de nieuwe markt om publieke waarden te respecteren zonder voor te schrijven hoe dat moet. Een ander beleidsprincipe is al harder: de zogenoemde right to challenge. Deze gaat uit van middelregelgeving, tenzij een betrokkene met een beter voorstel komt om publieke belangen te sparen. Dit idee werkt met middelregelgeving als een duidelijke stok achter de deur. De beleidsinstrumentatie zou ermee niet 'zacht, mits ...', maar 'hard, tenzij ...' worden.

De bijdrage van Spekkink, Teisman en Boons schetst een publiek-private verdeling van activiteiten in termen van project en programma en in termen van 'voorwas', met private projecten en publieke 'hoofdwas'. Zij maken een programmati- 
sche combinatie van projecten. Als zodanig schalen zij verschillende initiatieven op door deze te assembleren. Opvallend zijn de kwalificaties van de rollen: 'opschalen', 'assembleren' en in betweenness centrality. Uit de bijdrage blijkt dat er veel publieke professionaliteit en kennis nodig is om deze rollen te vervullen. Behalve inhoudelijke kennis is timing van belang. Wat is een geëigend moment om zich de verbindende positie aan te meten en een geloofwaardig en substantieel programma (mede) te ontwikkelen?

Meijer, Tomor, Michels en Geertman zien drie lokale overheden die innovaties van burgers accommoderen en bezig zijn hun rollen te definiëren. Burgers kwamen vooral op het netvlies van de overheid als ze een probleem waren (zorg) of een problemen vormen (veiligheid), maar worden nu, meer dan voorheen, gezien als medeoplosser van problemen, als co-creatoren en innovators. Sommige gemeenten zien burgers hooguit als informatiebron, waar anderen ervoor kiezen burgers juist te activeren als co-createur. De gemeente blijft echter wel stevig aanwezig. Het gaat dus niet om 'iets over de schutting gooien'. Twijfels over inclusie en democratie maakten gemeenten terughoudend om de regie uit handen te geven. Terughoudendheid geldt ook voor het gebruik van nieuwe technische mogelijkheden, omdat wellicht slechts 'een elite' daarvan gebruik gaat maken.

Een nieuw idee over waterveiligheid goed laten landen in een sterk geïnstitutionaliseerde organisatie blijkt geen sinecure, zo stellen Van Buuren en Ellen vast. Pilots definiëren, uitvoeren en evalueren durven overheden wel. Dat is winst. Maar deze te verankeren in de bestaande organisatie bleek een uitdaging van een andere orde. De auteurs problematiseren dit 'aanhechten en opschalen' en vragen zich af hoe overheden dit kunnen gaan zien als een gewenst en voldoende veilig leerproces. De strategie om dat proces tot een goed einde te brengen is klassiek: het is een kwestie van 'intelligent doormodderen' middels 'kleine stapjes en slimme duwtjes'.

We zien aldus overheden die weliswaar meebewegen, maar de tijd ook benutten om zichzelf te herpositioneren. Er worden nieuwe beleidsinstrumenten ontwikkeld, er worden relaties gelegd met de belangrijkste partijen om in innovatieprocessen te kunnen participeren, er wordt op verschillende manieren regie gehouden bij burgerparticipatie, en innovaties worden slim, incrementeel ingebracht in de primaire processen van overheden.

\section{De innoverende overheid: een stap verder dan Mazzucato}

Laten we nu terugkomen op de discussie die mede door het boek van Mazzucato is gestart. Is de overheid niet goed in innovatie? Misschien wel. De overheid heeft een ingewikkelde positie in innovatie. Innovatie brengt vrijwel altijd strijdigheid tussen publieke belangen aan het licht. Burgers verwachten van overheden dat ze hun belangen borgen. De overheid moet dus altijd voor innovatie zijn en tegen bijkomende nadelen. Bovendien formaliseren de waarborgen al vrij snel en hard. Ze moeten immers bestand zijn tegen eenieder die de publieke belangen schaadt. De prijs is verlies aan flexibiliteit jegens nieuwe ontwikkelingen. Overheden heb- 
ben reden genoeg te willen meebewegen, maar hebben tijd nodig om hun positie te herdefiniëren.

Cruciaal bij het bepalen van de positie van overheden is het behartigen van het publieke belang. Voor bedrijven is het niet erg als 20 procent van de bevolking een nieuwe app niet gebruikt, voor overheden is er dan sprake van een 'digitale kloof' die moet worden overbrugd. Voor Airbnb is het grote aantal overnachtingen alleen een succes, terwijl overheden ook te maken hebben met allerlei perverse en ongewenste effecten. Daarmee willen we de redenering van Mazzucato nog een stap doortrekken. Mazzucato liet zien dat overheden een belangrijke rol spelen bij het aanjagen van innovaties die belangrijk zijn voor economische groei. Dit themanummer laat zien dat overheden daar bovenop allerlei andere rollen aannemen, cruciaal voor andere publieke waarden. Zij faciliteren niet alleen de nieuwe partijen ('meebewegen'), maar borgen tegelijkertijd publieke waarden, waardoor de innovaties ook voor het bredere publiek acceptabel worden. Ze ontwikkelen nieuwe instrumenten, ze bundelen private initiatieven, ze framen deze initiatieven tot grote programma's, ze vernieuwen hun kanalen om deskundigheid van o.a. burgers toe te laten tot hun besluiten en ze vinden hun eigen taken soms opnieuw uit. Deze activiteiten zijn vaak niet meetbaar en ontbreken daarom in economische analyses. Dit themanummer agendeert onderzoek naar bijdragen van overheden aan de publieke waarde van innovatie.

De genoemde activiteiten omvatten complexe processen die niet gemakkelijk naar buiten te brengen zijn, ook al omdat ze langer duren dan in de publieke perceptie wellicht wordt verwacht. Zoals Mazzucato al aanstipte, is de overheid relatief onzichtbaar als facilitator van innovaties. Wellicht is er een behoefte aan verbale innovaties, waardoor de rollen van overheden bij grote innovaties beter tot hun recht komen?

\section{Literatuur}

Brandsen, T., Cattacin, S., Evers, A., \& Zimmer, A. (2016). Social Innovations in the Urban Context. Heidelberg: Springer.

Cooper, R.G. (1990). State-gate systems: A new tool for managing new products. Business Horizons, 33(3), 44-54.

Freeman, L. C. (1978). Centrality in social networks conceptual clarification. Social Networks, 1(3), 215-239.

Highsmith, J., \& Cockburn, A. (2001). Agile Software Development: The business of innovation. Computer, 34(9), 120-127.

Kemp, R., Schot, J.W., \& Hoogma, R. (1998). Regime shifts to sustainability through processes of niche formation: The approach of strategic niche management. Technology Analysis and Strategic Management, 10, 175-196.

Matson, J.V. (1996). Innovate or Die: A Personal Perspective on the Art of Innovation. Boulder: Paradigm Publishers.

Mazzucato, M. (2013). The Entrepreneurial State: Debunking public vs. private sector myths. London: Anthem Press.

Osborne, S.P., \& Brown, L. (2005). Managing Change and Innovation in Public Service Organizations. Milton Park: Routledge.

Rogers, E.M. (1995). Diffusion of Innovations (fourth edition). New York: The Free Press. 
Rotmans, J. (2003). Transitiemanagement. Assen: Van Gorcum.

Sørensen, E., \& Torfing, J. (2011). Enhancing Collaborative Innovation in the Public Sector. Administration and Society, 43(8), 842-868.

Vries, H. de, Bekkers, V., \& Tummers, L. (2015). Innovation in the public sector: A systematic review and future research agenda. Public Administration, 1-40. 